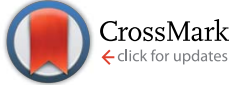

Cite this: J. Mater. Chem. A, 2015, 3, 12044

Received 6th April 2015

Accepted 24th April 2015

DOI: $10.1039 / c 5 t a 02486 b$

www.rsc.org/MaterialsA

\section{Reaction mechanism from quantum molecular dynamics for the initial thermal decomposition of 2,4,6-triamino-1,3,5-triazine-1,3,5-trioxide (MTO) and 2,4,6-trinitro-1,3,5-triazine-1,3,5-trioxide (MTO3N), promising green energetic materials $\uparrow$}

\author{
Cai-Chao Ye, ${ }^{\text {ab }}$ Qi An, ${ }^{a}$ Tao Cheng, ${ }^{a}$ Sergey Zybin, ${ }^{a}$ Saber Naserifar, ${ }^{a}$ Xue-Hai Ju ${ }^{b}$ \\ and William A. Goddard III
}

Klapötke and co-workers recently designed two new materials, 2,4,6-triamino-1,3,5-triazine-1,3,5-trioxide (MTO) and 2,4,6-trinitro-1,3,5-triazine-1,3,5-trioxide (MTO3N), envisioned as candidates for green highenergy materials. However, all attempts at synthesis have failed. In order to validate the expected properties for these systems and to determine why these materials are too unstable to synthesize, we used the PBE flavor of Density Functional Theory (DFT) to predict the crystal structures for MTO and MTO3N and then we carried out DFT molecular dynamics simulations (DFT-MD) to determine the initial reaction mechanisms for decomposition. Klapötke estimated that MTO would have a density of $\rho=1.859 \mathrm{~g} \mathrm{~cm}^{-3}$ with an estimated detonation velocity $\left(D_{v}\right)$ of $8.979 \mathrm{~km} \mathrm{~s}^{-1}$, making it comparable to $\operatorname{RDX}\left(\rho=1.82 \mathrm{~g} \mathrm{~cm}^{-3}\right.$, $\left.D_{v}=8.75 \mathrm{~km} \mathrm{~s}^{-1}\right)$ and $\beta-\operatorname{HMX}\left(\rho=1.91 \mathrm{~g} \mathrm{~cm}^{-3}, D_{v}=9.10 \mathrm{~km} \mathrm{~s}^{-1}\right)$. His estimated impact sensitivity $>30 \mathrm{~J}$, make it much better than $\operatorname{HMX}(7 \mathrm{~J})$ and RDX $(7.5 \mathrm{~J})$. Our predicted crystal structure for MTO $\left(P 2_{(1)}\right.$ space group) leads to $\rho=1.859 \mathrm{~g} \mathrm{~cm}^{-3}$, in good agreement with expectations. Our DFT-MD studies find that the first step in the decomposition of MTO is intermolecular hydrogen-transfer reaction (barrier $3.0 \mathrm{kcal} \mathrm{mol}^{-1}$ ) which is followed quickly by $\mathrm{H}_{2} \mathrm{O}$ and $\mathrm{NO}$ release with reaction barriers of 46.5 and $35.5 \mathrm{kcal} \mathrm{mol}^{-1}$. In contrast for MTO3N ( $P 2_{(1)} / c$ predicted space group), we find that the first steps are a bimolecular decomposition to release $\mathrm{NO}_{2}\left(\Delta H=44.1 \mathrm{kcal} \mathrm{mol}^{-1}, \Delta G=54.7 \mathrm{kcal} \mathrm{mol}^{-1}\right)$ simultaneous with unimolecular $\mathrm{NO}_{2}$ cleavage $\left(\Delta H=59.9\right.$ and $\left.\Delta G=58.2 \mathrm{kcal} \mathrm{mol}^{-1}\right)$ a unique initial reaction among EMs. These results suggest that MTO3N would be significantly more thermally stabile (barrier $>6.0 \mathrm{kcal} \mathrm{mol}^{-1}$ higher) than RDX and HMX, making it an excellent candidate to be insensitive new green energetic materials. However we find that MTO leads to very favorable hydrogen transfer reactions that may complicate synthesis and crystallization, making MTO3N the more promising system.

\section{Introduction}

Environmental concerns about current energetic materials (EM) make the development of green EM a high priority. ${ }^{1}$ Moreover developing safe and efficient high-energy content materials is of vital importance to utilization in civil applications as propellants in satellite launch rockets, satellite propulsions system, and naval systems., ${ }^{1,2}$ An ideal green explosive should have

\footnotetext{
${ }^{a}$ Materials and Process Simulation Center, California Institute of Technology, 139-74, Pasadena, California 91125, United States. E-mail: wag@wag.caltech.edu

${ }^{b}$ Key Laboratory of Soft Chemistry and Functional Materials of MOE, School of Chemical Engineering, Nanjing University of Science and Technology, Nanjing 210094, P. R. China

$\dagger$ Electronic supplementary information (ESI) available: Atomic coordinates of all intermediates and TSs shown in this study, coordinates for structures of $\boldsymbol{P 2} 2_{(1)}$-MTO and $\boldsymbol{P 2} 2_{(1)} / \mathbf{c}-\mathbf{M T O 3 N}$, and the bond cut-off in the fragment analysis. See DOI: $10.1039 / \mathrm{c} 5$ ta02486b
}

higher velocity of detonation, higher detonation pressure, higher density, and lower sensitivity than benchmark explosives, such as RDX and HMX. Simultaneously it is important that the end products from detonation or combustion are environmentally friendly and that the syntheses not yield toxic or non-green materials that must be disposed. For this reason Klapötke et al. designed 2,4,6-triamino-1,3,5-triazine-1,3,5trioxide (MTO) and 2,4,6-trinitro-1,3,5-triazine-1,3,5-trioxide (MTO3N) as potential new green energetic materials and estimated that velocity of detonation would be $8.979 \mathrm{~km} \mathrm{~s}^{-1}$ (compare to $8.855 \mathrm{~km} \mathrm{~s}^{-1}$ for RDX and $9.247 \mathrm{~km} \mathrm{~s}^{-1}$ for $\beta$-HMX) with density is $1.9 \mathrm{~g} \mathrm{~cm}^{-3}$ and impact sensitivity $>30 \mathrm{~J}$, much better than $\operatorname{HMX}(7 \mathrm{~J})$ and $\operatorname{RDX}(7.5 \mathrm{~J}) .^{3}$

However, numerous attempts to synthesize MTO and MTO3N have not yet been successful. In order to predict more accurately the properties and to understand the stability, we recently predicted ${ }^{4}$ the crystal packing and cohesive energy of 

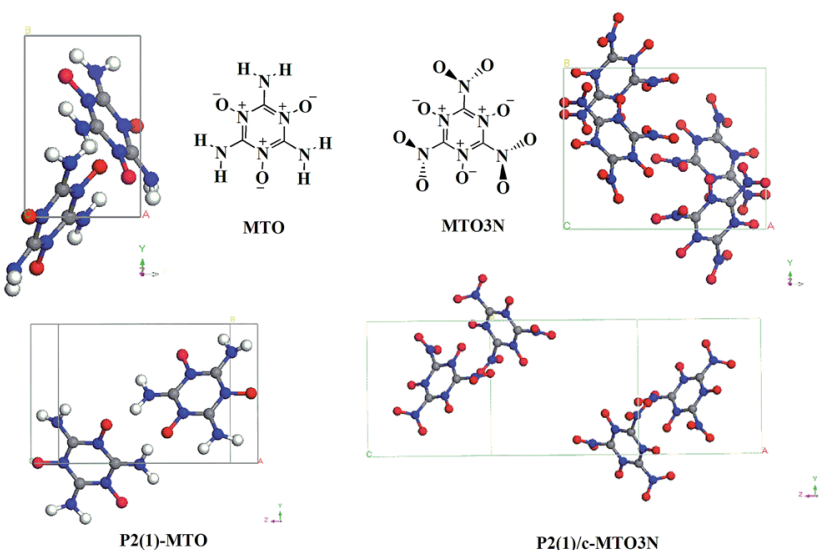

Fig. 1 2,4,6-Triamino-1,3,5-triazine-1,3,5-trioxide (MTO) and 2,4,6trinitro-1,3,5-triazine-1,3,5-trioxide (MTO3N) molecular structures and their most stable crystal structures: $P 2_{(1)}$ for $M T O$ and $P 2_{(1)} / C$ for MTO3N predicted from previous PBE DFT calculations. ${ }^{4}$ The $\mathrm{C}, \mathrm{O}, \mathrm{N}, \mathrm{H}$ atoms are represented by grey, red, blue and white balls, respectively.

MTO and MTO3N using Monte Carlo simulated annealing methods $^{5}$ with the PBE flavor of Density functional Theory ${ }^{6}$ (DFT) (including the low gradient London dispersion correction $)^{7}$ (PBE-ulg) to find that MTO has the $P 2_{(1)}$ space group with 2 molecules per cell and a density of $1.859 \mathrm{~g} \mathrm{~cm}^{-3}$, while MTO3N has the $P 2_{(1)} / c$ space group with 4 molecules per cell and a density of $2.016 \mathrm{~g} \mathrm{~cm}^{-3}$. The two molecules and crystal structures are shown in Fig. 1.

In order to determine the energy release, detonation properties, and sensitivity of EMs, it is essential to determine the reaction mechanism for the initial steps leading to thermal decomposition. ${ }^{\mathbf{8 - 1 4}}$ For such nitro-based EMs as TNT, RDX, HMX and CL-20, the initial decomposition at low pressure is unimolecular $\mathrm{NO}_{2}$ cleavage. ${ }^{15-20}$ However for hydrogen containing highly energetic materials such as RDX and HMX, Chakraborty et al. ${ }^{\mathbf{8 , 1 4 2 1}}$ used DFT to show that intramolecular hydrogen transfer to form HONO provides a competitive first step for decomposition ${ }^{22-27}$ that dominates under high impact conditions. ${ }^{28}$ Since MTO has no $-\mathrm{NO}_{2}$ group available to cleave off $\mathrm{NO}_{2}$, and MTO3N has no hydrogen available to form HONO, their decomposition properties should be dramatically different (maybe better) than normal nitro-based explosives.

In this paper, we report the initial thermal decomposition reaction mechanisms of MTO and MTO3N using molecular dynamics simulations based on the PBE-ulg ${ }^{7}$ flavor of DFT. The PBE-ulg corrects the poor description of van der Waals attraction (London dispersion) in PBE. ${ }^{7}$ Here we consider MTO and MTO3N starting with their predicted most stable crystal structures $\left(P 2_{(1)}\right.$ for MTO and $P 2_{(1)} / c$ for MTO3N).

\section{Methodology}

\subsection{Quantum molecular dynamics simulation}

In these DFT based molecular dynamics (MD) simulations, the interatomic forces were calculated in the framework of DFT, ${ }^{29,30}$ where exchange and correlation were treated with the generalized gradient approximation (GGA), using the PBE-ulg functional form. ${ }^{7}$

The periodic DFT calculations were performed using the VASP package. ${ }^{31-34}$ For structure optimization we found that a kinetic energy cut-off of $500 \mathrm{eV}$ for the plane wave expansions gives excellent convergence of the total energies, energy differences, and structural parameters. The same energy cut-offs were used in the DFT-MD calculations. Reciprocal space was sampled with the $\Gamma$-centered Monkhorst-Pack scheme using only the gamma point for the supercell calculations. The convergence criteria were set to a $1 \times 10^{-6} \mathrm{eV}$ energy difference for solving the electronic wave function and a $1 \times 10^{-3} \mathrm{eV}^{-1}$ force for geometry optimization. They were set to $1 \times 10^{-5} \mathrm{eV}$ energy difference for solving the electronic wave function and a $1 \times$ $10^{-3} \mathrm{eV} \AA^{-1}$ force for DFT-MD simulation.

Two crystalline phases (MTO: $P 2_{(1)}$ and MTO3N: $P 2_{(1)} / c$ ) were considered in the DFT-MD simulations. The MD considered 8 molecules per periodic cell, obtained by replicating the unit cell twice along the " $a$ " and " $b$ " directions for MTO and replicating the unit cell twice along the " $c$ " direction for MTO3N. Then the structures for the supercells were optimized individually before molecule dynamics simulations. The two initial structures of MTO-P2 $2_{(1)}$ and MTO3N-P2 $\mathbf{2}_{(\mathbf{1})} / \boldsymbol{c}$ are shown in Fig. S1. $\dagger$

The procedure for the DFT-MD cook-off simulations was as follows: first the systems were heated from $20 \mathrm{~K}$ to $300 \mathrm{~K}$ over a period of $2 \mathrm{ps}$ and then equilibrated at $300 \mathrm{~K}$ for $1 \mathrm{ps}$ using the NVT (constant volume, constant temperature and constant number of atoms) ensemble. Finally, we heated the system from $300 \mathrm{~K}$ to $3000 \mathrm{~K}$ uniformly over the period of $20 \mathrm{ps}$, but with the volume fixed. The time constant for the Nose-Hoover thermostat was set to $0.1 \mathrm{ps}$. We used a time step of $1 \mathrm{fs}$ for integrating the equations of motion. To analyse the fragments during the simulation, we used a bond length cut-off of 1.5 times of the normal bond length, as are shown in the Table S1.†

\subsection{Finite cluster calculation}

To analyse the mechanisms for the reactions discovered during the periodic DFT-MD simulations, we extracted the molecule structures involved (generally bimolecular) in the reaction from the periodic DFT-MD trajectories and then carried out finite molecule calculations to locate the nearby transition state (TS) for gas phase reactions at the level of $\mathrm{M} 06 / 6-311++\mathrm{G}^{* *}$ using the Jaguar program. ${ }^{35}$ The TS's were validated to have only one negative eigenvalue for the Hessian. This was followed by intrinsic reaction coordinate (IRC) scans to connect the TS to nearby reactant and the product structures. ${ }^{36}$ To obtain free energies, we diagonalized the mass reduced Hessian to obtain the vibrational frequencies, with which we evaluated the thermodynamic properties at $298.15 \mathrm{~K}$ and 1 atm. All gas phase calculations were carried out using the Jaguar 8.2 package. $^{35}$

\section{Results and discussion}

These DFT-MD simulations provide a very detailed, molecularlevel description of the decomposition and reactions of MTO and MTO3N in the condensed phase. This information allows 
us to extract valuable information about the complex chemistry involved, including uni- and multi-molecular reactions. ${ }^{12}$ Our goal is to elucidate the reaction pathway as MTO and MTO3N decomposes and evolves to form intermediates that react with each other and with reactant to form eventually the final products observed theoretically and presumably experimentally. In this work, we focus on thermal decomposition of condensed phase MTO and MTO3N crystals, examining the initial reaction pathways to evaluate the stability of these two promising green energetic materials.

\subsection{MTO initial reaction}

3.1.1. Quantum molecular dynamics simulation. We first examined the initial decomposition reaction of $\boldsymbol{P 2}_{(\mathbf{1})}$-MTO. The molecular fragments during the cook-off simulation are plotted in Fig. 2 as a function of temperature. The starting supercell consists of 8 MTO molecules (144 atoms). We see that

1. No reactions are observed from 0 to $7 \mathrm{ps}$ (up to $1250 \mathrm{~K}$ ).

2. Simultaneous intermolecular $\mathrm{H}$ transfer between two MTO monomers is observed during the period 7 to 11 ps (up to 1700 $\mathrm{K}$ ) to form the dimer containing adjacent $\mathrm{NH}$ and $\mathrm{N}-\mathrm{OH}$ groups in place of $\mathrm{NH}_{2}$ and $\mathrm{N}-\mathrm{O}^{-}$, with a structure similar to TS1 in Fig. 3.

3. Then, at $11.5 \mathrm{ps}(\sim 1800 \mathrm{~K})$ the first reaction occurs, a unimolecular reaction involving the intermediate formed in step 2 in which an $\mathrm{NH}_{2}$ transfer a hydrogen to the $\mathrm{N}-\mathrm{OH}$ group to release $\mathrm{H}_{2} \mathrm{O}$, leaving behind INT2 (Fig. 3) with an opened ring.

4. Later at $13 \mathrm{ps}(\sim 2050 \mathrm{~K})$, the first NO molecule is released from INT2.

Thus, we find that the unimolecular $\mathrm{H}_{2} \mathrm{O}$ release subsequent to $\mathrm{H}$ transfers between two monomers is the initial decomposition reaction for $\boldsymbol{P 2}_{(\mathbf{1})}$-MTO. We will discuss these reaction mechanisms in more detail using finite cluster calculations. As

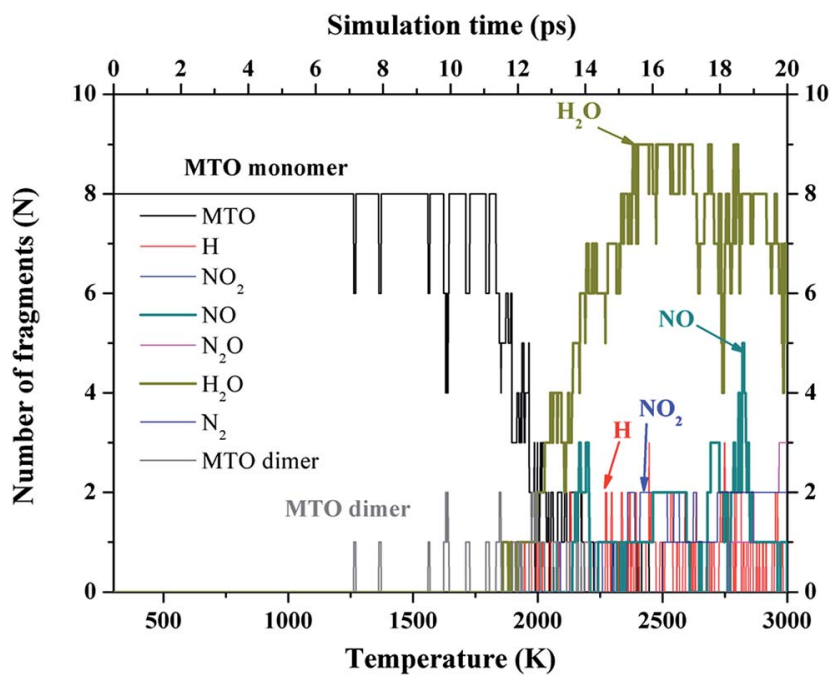

Fig. 2 Species analysis for the decomposition of $P 2_{(1)}-$ MTO heated from 300 to $3000 \mathrm{~K}$ over $20 \mathrm{ps}$. During 7 to $11 \mathrm{ps,} \mathrm{H}$ transfer occurs and at $\sim 11.5 \mathrm{ps}(T=1800 \mathrm{~K})$, the first $\mathrm{H}_{2} \mathrm{O}$ released. Starting at $13 \mathrm{ps}(\sim 2050$ $\mathrm{K})$, one NO molecule is released. The main product of MTO decomposition is $\mathrm{H}_{2} \mathrm{O}$. the temperature continues to increase, we observe the release of increased numbers of $\mathrm{H}_{2} \mathrm{O}$ products.

3.1.2. Finite cluster calculations. To understand the nature of the initial decomposition reactions of $\boldsymbol{P 2} \mathbf{2}_{(\mathbf{1})}$-MTO, we extracted the activated intermediates from the condensed phase simulation and analyzed the reaction mechanism as a gas phase reaction.

3.1.2a. Intermolecular $H$ transfer to form INT1 (MTO-TS1INT1). We find that the first reaction is intermolecular hydrogen-transfer in which two MTO molecules each exchange one $\mathrm{H}$ atom with the other to form the intermediate INT1 (Fig. 3) via TS1. This leads to a very low barrier of only $\Delta H=3.0$ kcal mol ${ }^{-1}\left(\Delta G=5.1 \mathrm{kcal} \mathrm{mol}^{-1}\right)$, which is very fast in the QMMD above $1250 \mathrm{~K}$. Based on this barrier and we estimate that this should take place in a nanosecond at room temperature, suggesting that the crystallization must be done at low temperature (below $50 \mathrm{~K}$ ). Although INT1 has an internal energy of $7.0 \mathrm{kcal} \mathrm{mol}^{-1}$, which is lower than the TS1 of $7.8 \mathrm{kcal} \mathrm{mol}^{-1}$ at zero temperature, we find that at room temperature INT1 has a higher enthalpy and free energy than the TS1.

3.1.2b. Decomposition of INT1' to release $\mathrm{H}_{2} \mathrm{O}$ (INT1'-TS2INT2 $+\mathrm{H}_{2} \mathrm{O}$ ). After formation of the INT1' (INT1 monomer) via the bimolecular $\mathrm{H}$ transfer from MTO, we find that one $\mathrm{H}$ atom of $-\mathrm{NH}_{2}$ transfers from the $\mathrm{N}$ atom to the nearby $\mathrm{OH}$ group via TS2 to release one $\mathrm{H}_{2} \mathrm{O}$ molecule and INT2, with a barrier of $\Delta H$ $=46.5 \mathrm{kcal} \mathrm{mol}^{-1}\left(\Delta G=46.4 \mathrm{kcal} \mathrm{mol}^{-1}\right)$, making it the ratedetermining step (RDS) for decomposition. Indeed this is the first decomposition process we see in the DFT-MD on the periodic system (at $\sim 11.5 \mathrm{ps}$ ).

3.1.2c. Decomposition of INT2 to release $\mathrm{NO}^{+}$(INT2-TS3INT3 $+\mathrm{NO}^{+}$). Starting with INT2, the lowest energy pathway to eliminate the $\mathrm{NO}^{+}$molecule is to break the $\mathrm{C}-\mathrm{N}$ bond via TS3 to form an intermediate INT3 (shown in Fig. 3), which we find to have a barrier of $35.5 \mathrm{kcal} \mathrm{mol}^{-1}$ above INT2. Indeed we see this process in the DFT-MD on the periodic system at $13 \mathrm{ps}$.

3.1.2d. MTO get one $\mathrm{H}^{+}$from previous decomposed nearby fragments. Between 12.5 and $15.0 \mathrm{ps}(2000 \mathrm{~K}$ and $2300 \mathrm{~K})$ in the DFT-MD simulations on MTO crystal, we found intermediates INT4, INT5 and INT6 after the first $\mathrm{H}_{2} \mathrm{O}$ and NO releasing reaction, (shown in Fig. 4). The mechanism for forming these species is as follows. First, the MTO molecule adds a dissociated $\mathrm{H}^{+}$from some previous decomposition to the $\mathrm{O}$ atom to form the intermediate INT4. Then starting from INT4, one $\mathrm{H}$ atom of $-\mathrm{NH}_{2}$ transfers via TS4 to the nearby $\mathrm{OH}$ group to release one $\mathrm{H}_{2} \mathrm{O}$ molecule, forming INT5. This has a barrier of $\Delta H=45.4$ kcal $\mathrm{mol}^{-1}\left(\Delta G=44.4 \mathrm{kcal} \mathrm{mol}^{-1}\right)$, making it the rate-determining step (RDS) for this decomposition pathway. Then from INT5 the easiest decomposition pathway is to eliminate the $\mathrm{NO}^{+}$ molecule by breaking the $\mathrm{C}-\mathrm{N}$ bond via TS5 to form intermediate INT6 (shown in Fig. 4), This has a barrier of $\Delta H=28.2 \mathrm{kcal}$ $\mathrm{mol}^{-1}\left(\Delta G=30.3 \mathrm{kcal} \mathrm{mol}^{-1}\right)$ above INT5.

3.1.2e. Intramolecular $H$ transfer (MTO-TS6-INT1'). Although our DFT-MD studies of MTO did not find an intramolecular hydrogen-transfer, we carried out QM calculations to examine the barrier for this intramolecular hydrogen-transfer pathway (MTO-TS6-INT1'), as shown in Fig. 5. Here one $\mathrm{H}$ atom of the $-\mathrm{NH}_{2}$ group transfers to the adjacent $\mathrm{O}$ atom to form the 
(a)

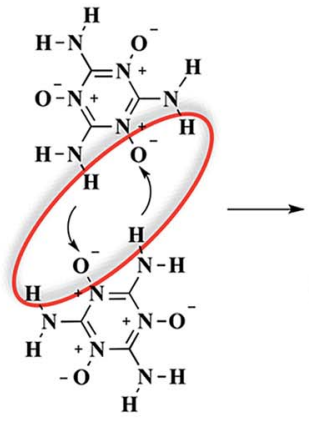

MTO

$\mathbf{H}=\mathbf{0}$

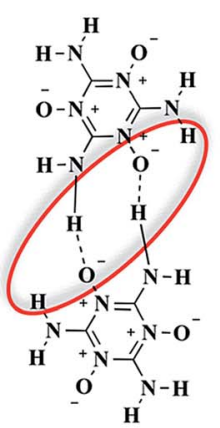

TS1

$\mathrm{H}=\mathbf{3 . 0}$

$\mathrm{G}=\mathbf{5 . 1}$

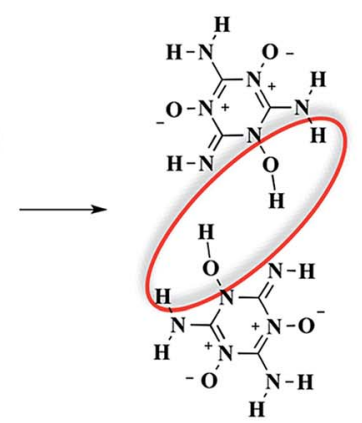

INT1

$\mathrm{H}=4.5$

$\mathrm{G}=6.5$

(b)

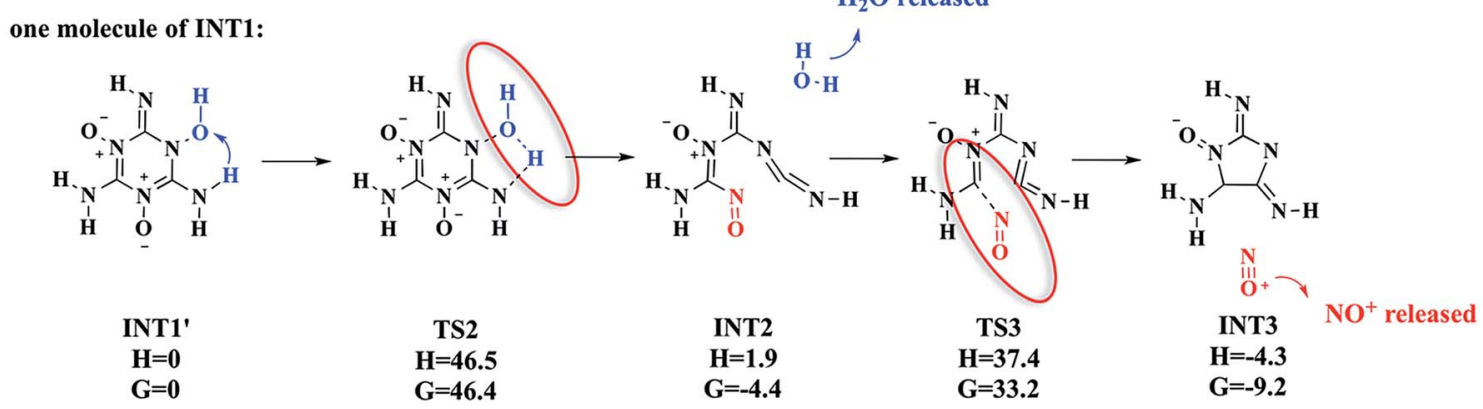

Fig. 3 The mechanism of the (a) intermolecular hydrogen-transfer, and (b) $\mathrm{H}_{2} \mathrm{O}$ and $\mathrm{NO}$ releasing reactions for MTO. First a bimolecular intermolecular hydrogen-transfer take place to form INT1, then one $\mathrm{H}_{2} \mathrm{O}$ is released to form INT2, which is followed quickly by $\mathrm{NO}^{+}$release to form INT3. Configurations TS1, INT1, TS2, INT2 and INT3 were extracted from the DFT-MD trajectory and then optimized as a gas phase reaction. We carried out IRC calculations to show that these steps are connected (that is there is no additional TS between MTO, INT1, INT2, and INT3). We calculate that the QM energy of the INT1 is $7.0 \mathrm{kcal} \mathrm{mol}{ }^{-1}$ lower than the TS1 of $7.8 \mathrm{kcal} \mathrm{mol}^{-1}$ at $0 \mathrm{~K}$, the INT1 has a higher enthalpy and free energy at $298.15 \mathrm{~K}$ than the TS1. Whereas including the hydrogen bonding between the two INT1' molecules in INT1, the QM energy of the INT1 ${ }^{\prime}$ is $4.0 \mathrm{kcal} \mathrm{mol}^{-1}$ above the INT1. Here energies are in $\mathrm{kcal} \mathrm{mol}^{-1}$. The $\Delta H$ and $\Delta G$ is evaluated at $298.15 \mathrm{~K}$.

get one $\mathrm{H}^{+}$from previous decomposition of a nearby MTO

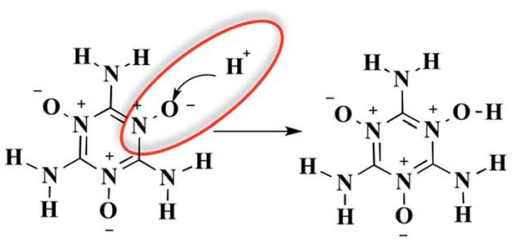

MTO
INT4

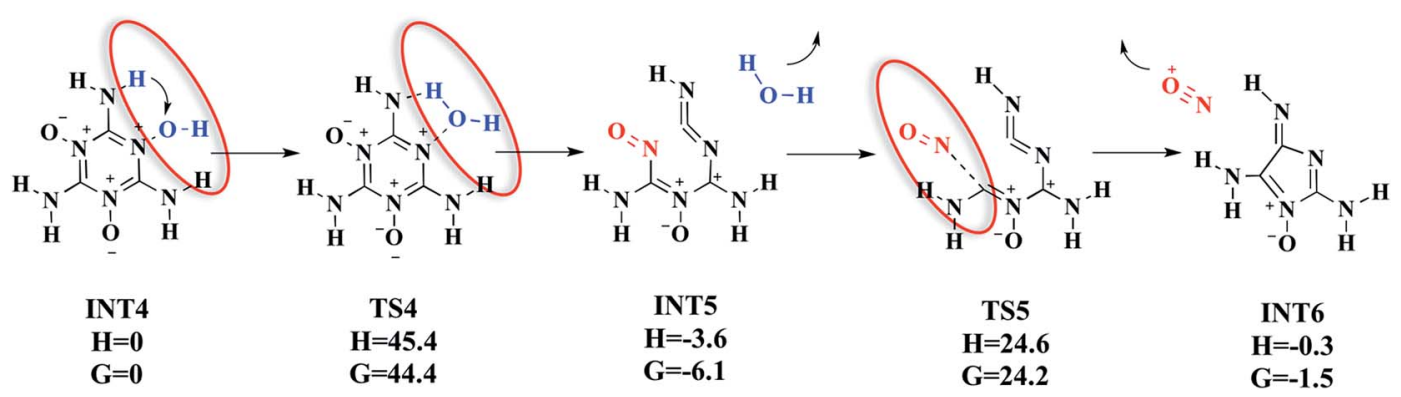

Fig. 4 The mechanism of our proposed pathway for the reactions releasing $\mathrm{H}_{2} \mathrm{O}$ and $\mathrm{NO}^{+}$from $\mathrm{MTO}$, which starts with an $\mathrm{H}^{+}$transfer from a previously decomposed MTO molecule to an oxygen atom (see the red lines in Fig. 2, which indicate dissociated $\mathrm{H}$ atoms) of an unreacted MTO to form INT4. Then INT4 releases one $\mathrm{H}_{2} \mathrm{O}$ to form INT5, which is followed quickly by $\mathrm{NO}^{+}$release to form INT6. Units are in kcal mol ${ }^{-1}$. 
INT1 via TS6. This leads to a barrier of $\Delta H=12.0 \mathrm{kcal} \mathrm{mol}^{-1}$ $\left(\Delta G=12.5 \mathrm{kcal} \mathrm{mol}^{-1}\right)$, which is $9.0 \mathrm{kcal} \mathrm{mol}^{-1}$ higher than the simultaneous intermolecular hydrogen-transfer reaction. This explains why we did not observe intramolecular hydrogentransfer events in the DFT-MD for periodic MTO. This pathway would form the same INT1' intermediate (one molecule in INT1) in the gas phase as shown in Fig. 5. As described above we also found a nearby transition state (TS6) with one saddle point and then the nearby stable reactant (MTO) and product (INT1') species. Compared with the intermolecular $\mathrm{H}$ transfer (discussed above in Fig. 3), the first INT1 in Fig. 3 has lower energy than INT1' in Fig. 5 because of the hydrogen bonding between the two INT1' molecules in INT1 (the hydrogen bond distance is $1.560 \AA$ ).

\subsection{MTO3N initial reaction}

3.2.1. Quantum molecular dynamics simulation. For $\boldsymbol{P 2} 2_{(1)} /$ c-MTO3N the initial decomposition fragments during the cookoff simulation are plotted in Fig. 6 as a function of time (temperature). The starting supercell consists of 8 MTO3N molecules (144 atoms).

- From 5 to $12.5 \mathrm{ps}$, the amplitude of the $\mathrm{N}-\mathrm{N}$ bond stretching vibration leads to fluctuations beyond our NN cut-off, but no real reactions.

- Then at 12.5 ps $(\sim 2000 \mathrm{~K})$, we observe release of two $\mathrm{NO}_{2}$ molecules simultaneously with three new fragments: MTO3N-NO ${ }_{2}$, MTO3N-O, and MTO3N-NO + O as shown in Fig. 6. Here one $\mathrm{NO}_{2}$ molecule comes from a bimolecular $\mathrm{NO}_{2}$ releasing reaction while the other is from a unimolecular $\mathrm{NO}_{2}$ cleavage reaction.

We will discuss the reaction mechanisms in more detail in the next section using finite cluster calculations. As the temperature continues increasing, we observe release of additional $\mathrm{NO}_{2}$ products.

3.2.2. Finite cluster calculation. In order to understand the nature of the initial decomposition reactions of $\boldsymbol{P 2} \mathbf{2}_{(\mathbf{1})} / \mathbf{c}-\mathbf{M T O 3 N}$, we extracted the activated intermediates from the condensed phase simulation and analyzed the reaction mechanism as a gas phase reaction, just as for $\boldsymbol{P 2}_{(\mathbf{1})}$-MTO. We find that both an initial bimolecular $\mathrm{NO}_{2}$ releasing reaction and a unimolecular $\mathrm{NO}_{2}$ cleavage reaction takes place simultaneously.

The bimolecular $\mathrm{NO}_{2}$ releasing reaction MTO3N-TS7-INT8 shown in Fig. 7(a) takes place between two MTO3N molecules at about $12.5 \mathrm{ps}(\sim 2000 \mathrm{~K})$. In this reaction one oxygen atom of an

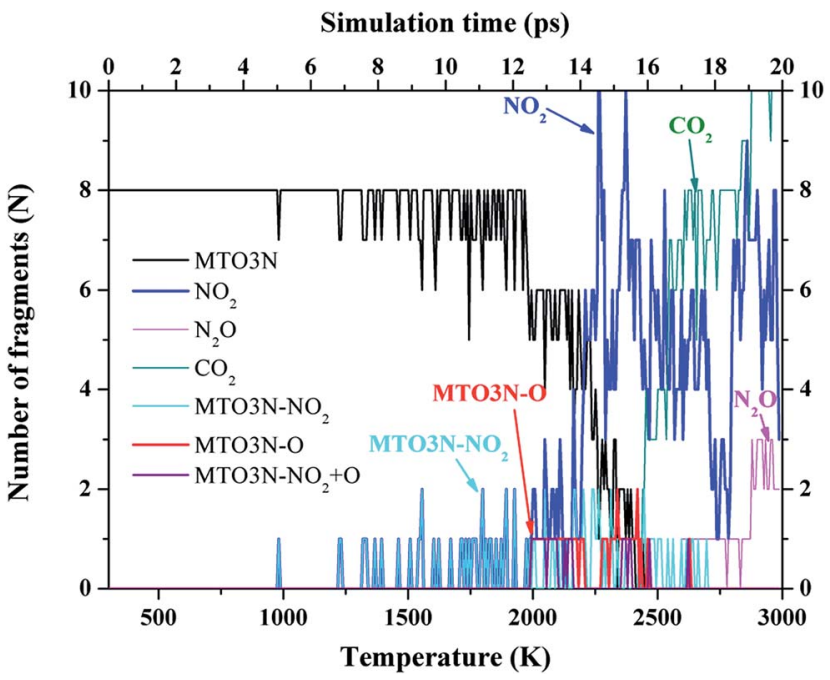

Fig. 6 Species analysis for the decomposition of $P 2_{(1)} / c-M T O 3 N$ heated from 300 to $3000 \mathrm{~K}$ over 20 ps. From 5 to 12.5 ps, we observe only $\mathrm{N}-\mathrm{N}$ bond stretching vibration (no reactions), and then at $12.5 \mathrm{ps}$ ( $2000 \mathrm{~K}$ ), we observe release of two $\mathrm{NO}_{2}$ molecules. At the same time, we observe three new fragments $\left(\mathrm{MTO} 3 \mathrm{~N}-\mathrm{NO}_{2}, \mathrm{MTO} \mathrm{N}-\mathrm{O}\right.$, and $\mathrm{MTO} 3 \mathrm{~N}-\mathrm{NO}_{2}+\mathrm{O}$ ), which indicate that the two $\mathrm{NO}_{2}$ molecules come both from a bimolecular $\mathrm{NO}_{2}$ releasing reaction and a unimolecular $\mathrm{NO}_{2}$ cleavage reaction. This event is illustrated in Fig. 7.

$-\mathrm{NO}_{2}$ group in MTO3N reacts with the carbon atom of the nearby MTO3N to make a new $\mathrm{C}=\mathrm{O}$ double bond via $\mathbf{T S 7}$, accompanied by breaking of the $\mathrm{C}-\mathrm{N}$ bond, to release one $\mathrm{NO}_{2}$. This bimolecular $\mathrm{NO}_{2}$ releasing reaction (MTO3N-TS7-INT8) is the ratedetermining step (RDS) with a barrier of $\Delta H=44.1 \mathrm{kcal} \mathrm{mol}^{-1}$ $\left(\Delta G=54.7 \mathrm{kcal} \mathrm{mol}^{-1}\right)$, which is similar to the barrier of $\mathrm{H}_{2} \mathrm{O}$ releasing reaction (INT1' ${ }^{\prime}$-TS2-INT2) in MTO initial reactions.

Fig. 7(b) shows, the energetics for the unimolecular $\mathrm{NO}_{2}$ cleavage reaction pathway (MTO3N-INT9) found in the fragment analysis of Fig. 6 at 12.5 ps $(\sim 2000 \mathrm{~K})$. The reaction barrier (and endothermicity) is calculated to be $\Delta H=59.9 \mathrm{kcal} \mathrm{mol}^{-1}$ (see Fig. 7(b)), which is $15.8 \mathrm{kcal} \mathrm{mol}^{-1}$ higher than the bimolecular $\mathrm{NO}_{2}$ releasing reaction barrier. However the transition state free energy $\Delta G=58.2$ at $298.15 \mathrm{~K}$ is similar to the $\Delta G=54.7$ for the bimolecular reaction, explaining why the DFT-MD simulation observes both at the same time at $12.5 \mathrm{ps}$ $(\sim 2000 \mathrm{~K})$.

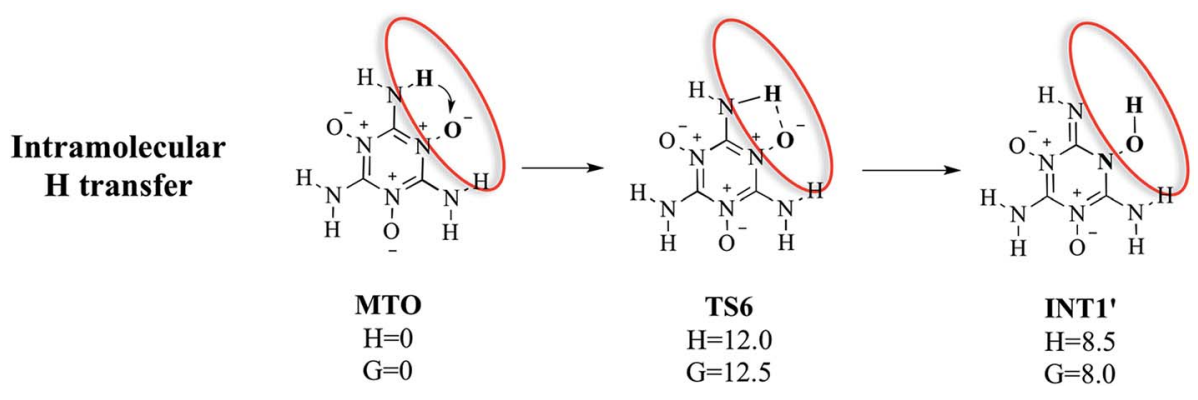

Fig. 5 The reaction mechanism for the intramolecular $\mathrm{H}$ transfer path MTO-TS6-INT1' that forms one molecule of INT1, this path was observed in gas phase but was not observed in the DFT-MD simulations. Here energies are in $\mathrm{kcal} \mathrm{mol}^{-1}$. 
(a)

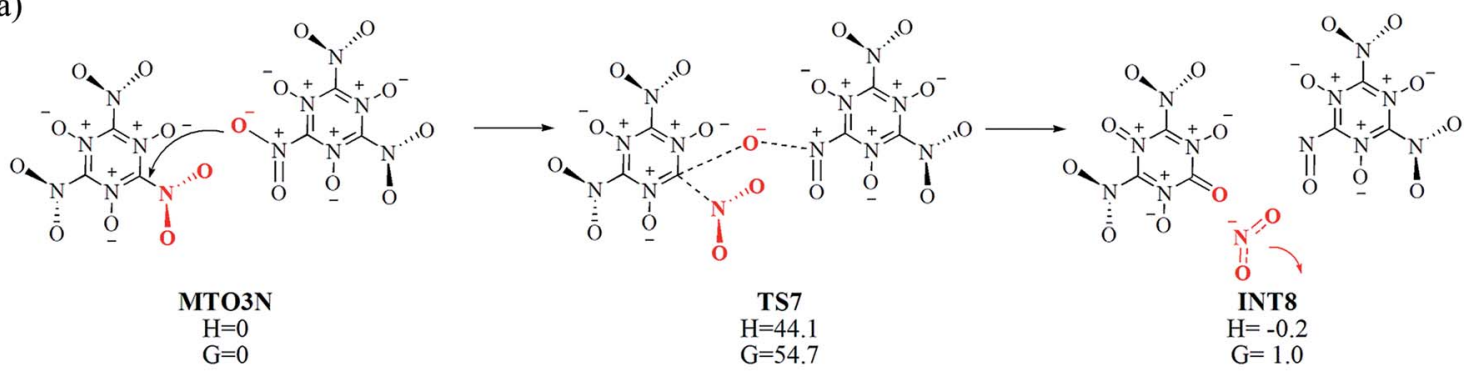

(b)

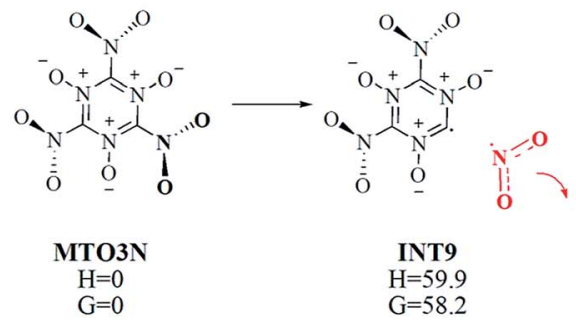

Fig. 7 (a) The mechanism of the bimolecular $\mathrm{NO}_{2}$ releasing reaction MTO3N-TS7-INT8, which takes place between two MTO3N molecules at $12.5 \mathrm{ps}(\sim 2000 \mathrm{~K})$. In this reaction one oxygen atom of the $-\mathrm{NO}_{2}$ group in MTO3N reacts with the carbon atom of a nearby MTO3N to make a new $\mathrm{C}=\mathrm{O}$ double bond via TS7 while displacing the $\mathrm{NO}_{2}$ from this $\mathrm{C}$ atom. (b) The unimolecular $\mathrm{NO}_{2}$ cleavage reaction for MTO3N. MTO3NINT9 also takes place at $12.5 \mathrm{ps}(\sim 2000 \mathrm{~K})$ Energies in $\mathrm{kcal} \mathrm{mol}^{-1}$. This reactions have very different $\Delta H$ with (a) much more favorable, but the $\Delta G$ at $298.15 \mathrm{~K}$ is similar.

To understand why the reaction energy (barrier) for the unimolecular $\mathrm{NO}_{2}$ cleavage reaction in MTO3N is much higher than the barrier of the bimolecular $\mathrm{NO}_{2}$ releasing reaction, we examined the molecular structure of MTO3N in both the gas phase and crystal. We found that optimizing the MTO3N molecular structure in the gas phase leads to a structure in which, the planes of the three $-\mathrm{NO}_{2}$ group are all perpendicular to the plane of 6-member ring. However, in the optimized MTO3N crystal, the angles between the planes of the $-\mathrm{NO}_{2}$ groups on one MTO3N molecule and the plane of 6-member ring are $30^{\circ}, 60^{\circ}$, and $90^{\circ}$, respectively. Moreover in the MTO3N crystal the shortest distance between the oxygen atom of $-\mathrm{NO}_{2}$ and the oxygen atom of nearby $\mathrm{C}=\mathrm{O}$ group is $2.655 \AA$, much shorter than in gas phase MTO3N (3.274 $\AA$ ). We conclude that the strong intermolecular repulsive force between $-\mathrm{NO}_{2}$ group and the nearby $\mathrm{C}=\mathrm{O}$ group makes the bimolecular release of the $-\mathrm{NO}_{2}$ group more favorable in the crystal. In contrast for unimolecular $\mathrm{NO}_{2}$ cleavage unimolecular $\mathrm{NO}_{2}$ cleavage in MTO3N requires a very long atom transfer process, giving it a very high reaction energy (barrier), but this is favored at high temperature because of the increased entropy from the bond breaking process.

\section{Summary and conclusions}

The condensed phase DFT-MD temperature programmed simulations uncover competing unimolecular and bimolecular reactions for the initial thermal decomposition reactions of the MTO and MTO3N energetic materials. We find that these MD results can be explained in terms reaction pathways on just the one or two molecules involved. Key points of our simulations are:

(1) For $\boldsymbol{P 2} \mathbf{2}_{(1)}$-MTO, the initial reaction is a bimolecular hydrogen-transfer reaction, followed first by $\mathrm{H}_{2} \mathrm{O}$ release with ring opening and then by $\mathrm{NO}^{+}$release. This intermolecular hydrogen-transfer reaction has a very low barrier of $\Delta H=3.0$ and $\Delta G=5.1 \mathrm{kcal} \mathrm{mol}^{-1}$, suggesting that this reaction may proceed in less than an hour even at $100 \mathrm{~K}$. This could be tested by examining the IR and Raman of the crystalline form to find evidence of both $\mathrm{OH}$ and $\mathrm{C}=\mathrm{N}$ bonds. For the INT1 species formed after the intermolecular hydrogen transfer reactions, it is now most favorable for intramolecular release of $\mathrm{H}_{2} \mathrm{O}(\Delta H=$ 46.5 and $\Delta G=46.4 \mathrm{kcal} \mathrm{mol}^{-1}$ ) to form INT2. From this INT2 intermediate, it is favourable $(\Delta H=35.5$ and $\Delta G=37.6 \mathrm{kcal}$ $\mathrm{mol}^{-1}$ ) to break the $\mathrm{C}-\mathrm{N}$ bond, to release $\mathrm{NO}^{+}$while forming an imidazole ring.

(2) For $\boldsymbol{P 2}(\mathbf{1}) / \mathbf{c}-\mathbf{M T O} 3 \mathbf{N}$, the bimolecular $\mathrm{NO}_{2}$ releasing reaction and unimolecular $\mathrm{NO}_{2}$ cleavage reaction take place simultaneously in the DFT-MD. In the bimolecular $\mathrm{NO}_{2}$ releasing reaction, one oxygen atom of the $-\mathrm{NO}_{2}$ group in MTO3N reacts with the carbon atom of a nearby MTO3N to form a new $\mathrm{C}=\mathrm{O}$ double bond while releasing the $\mathrm{NO}_{2}$ from this carbon, with a $\Delta H=44.1$ and $\Delta G=54.7 \mathrm{kcal} \mathrm{mol}^{-1}$ barrier. The reaction energy (barrier) for the unimolecular $\mathrm{NO}_{2}$ cleavage is calculated to be $\Delta H=59.9$ and $\Delta G=58.2 \mathrm{kcal} \mathrm{mol}^{-1}$ leading to a $\Delta G$ just slightly higher than the bimolecular $\mathrm{NO}_{2}$ releasing reaction.

The predicted initial reaction barriers for MTO $(\Delta H=46.5$ kcal mol$\left.{ }^{-1}\right)$ and MTO3N $\left(\Delta H=44.1 \mathrm{kcal} \mathrm{mol}^{-1}\right)$ are higher than the $\mathrm{NO}_{2}$ dissociation barrier $\mathrm{RDX}\left(\Delta H=39.0 \mathrm{kcal} \mathrm{mol}^{-1}\right)^{8}$ and for $\operatorname{HMX}^{14}\left(\Delta H=39.8 \mathrm{kcal} \mathrm{mol}^{-1}\right)$. This suggests that both 
crystals should be more thermally stable. However the favourable hydrogen transfer processes in MTO may lead to problems with synthesis and crystallization. Thus we recommend MTO3N as the more promising material.

We have carried out similar DFT-MD simulations to investigate the initial thermal decomposition reaction of TKX-50 ${ }^{37}$ and DTTO, ${ }^{38}$ which also have been suggested to be insensitive energetic materials. There we found the first decomposition barrier of TKX-50 (45.1 kcal mol ${ }^{-1}$ ) and DTTO (45.9 kcal mol ${ }^{-1}$ ), which are similar to the value we find for MTO $\left(46.5 \mathrm{kcal} \mathrm{mol}^{-1}\right)$ and MTO3N (44.1 kcal $\mathrm{mol}^{-1}$ ). These high decomposition barriers for MTO and MTO3N suggest that these newly designed green energetic materials: MTO and MTO3N would be thermally insensitive.

\section{Conflict of interest}

The authors declare no competing financial interest.

\section{Acknowledgements}

This research was funded by ONR (N00014-09-1-0634, Cliff Bedford). C.-C. Ye was sponsored by the China Scholarship Council, and thanks the Innovation Project for Postgraduates in Universities of Jiangsu Province (Grant no. CXZZ13_0213).

\section{References}

1 M. B. Talawar, R. Sivabalan, T. Mukundan, H. Muthurajan, A. K. Sikder, B. R. Gandhe and A. S. Rao, J. Hazard. Mater., 2009, 161, 589-607.

2 D. M. Badgujar, M. B. Talawar, S. N. Asthana and P. P. Mahulikar, J. Hazard. Mater., 2008, 151, 289-305.

3 T. M. Klapötke, personal communication, 2014.

4 S. Naserifar, S. V. Zybin, C.-C. Ye and W. A. Goddard III, 2015, unpublished.

5 M. Arellano and S. Bond, Rev. Econ. Stud., 1991, 58, 277-297. 6 R. G. Parr and R. G. P. W. Yang, Density-functional theory of atoms and molecules, Oxford University Press, 1989.

7 H. Kim, J. M. Choi and W. A. Goddard III, J. Phys. Chem. Lett., 2012, 3, 360-363.

8 D. Chakraborty, R. P. Muller, S. Dasgupta and W. A. Goddard III, J. Phys. Chem. A, 2000, 104, 2261-2272.

9 N. Umezawa, R. K. Kalia, A. Nakano, P. Vashista and F. Shimojo, J. Chem. Phys., 2007, 126, 234702.

10 R. A. Fifer, Fundamentals of Solid-Propellant Combustion, AIAA, New York, 1984.

11 M. R. Manaa, L. E. Fried, C. F. Melius, M. Elstner and T. Frauenheim, J. Phys. Chem. A, 2002, 106, 9024-9029.

12 S. P. Han, A. C. van Duin, W. A. Goddard III and A. Strachan, J. Phys. Chem. B, 2011, 115, 6534-6540.

13 A. Strachan, E. M. Kober, A. C. van Duin, J. Oxgaard and W. A. Goddard III, J. Chem. Phys., 2005, 122, 54502.
14 D. Chakraborty, R. P. Muller, S. Dasgupta and W. A. Goddard III, J. Phys. Chem. A, 2001, 105, 1302-1314.

15 S. N. Bulusu, Chemistry and physics of energetic materials, Kluwer Academic, Boston Norwell, MA, U.S.A., 1990.

16 C. J. Wu and L. E. Fried, J. Phys. Chem. A, 1997, 101, 86758679.

17 K. K. Irikura, J. Phys. Chem. A, 2013, 117, 2233-2241.

18 R. Cohen, Y. Zeiri, E. Wurzberg and R. Kosloff, J. Phys. Chem. A, 2007, 111, 11074-11083.

19 X. F. Chen, J. F. Liu, Z. H. Meng and K. L. Han, Theor. Chem. Acc., 2010, 127, 327-344.

20 S. Okovytyy, Y. Kholod, M. Qasim, H. Fredrickson and J. Leszczynski, J. Phys. Chem. A, 2005, 109, 2964-2970.

21 D. Chakraborty, R. P. Muller, S. Dasgupta and W. A. Goddard III, J. Comput.-Aided Mol. Des., 2002, 8, 203-212.

22 B. Wang, D. Wright, D. Cliffel, R. Haglund and S. T. Pantelides, J. Phys. Chem. A, 2011, 115, 8142-8146.

23 D. Furman, R. Kosloff, F. Dubnikova, S. V. Zybin, W. A. Goddard III, N. Rom, B. Hirshberg and Y. Zeiri, J. Am. Chem. Soc., 2014, 136, 4192-4200.

24 C. A. Mayhew, P. Sulzer, F. Petersson, S. Haidacher, A. Jordan, L. Mark, P. Watts and T. D. Mark, Int. J. Mass Spectrom., 2010, 289, 58-63.

25 Z. Takats, I. Cotte-Rodriguez, N. Talaty, H. W. Chen and R. G. Cooks, Chem. Commun., 2005, 1950-1952.

26 L. M. Minier, K. R. Brower and J. C. Oxley, J. Org. Chem., 1991, 56, 3306-3314.

27 L. L. Davis and K. R. Brower, J. Phys. Chem., 1996, 100, 18775-18783.

28 A. Strachan, A. C. van Duin, D. Chakraborty, S. Dasgupta and W. A. Goddard III, Phys. Rev. Lett., 2003, 91, 098301.

29 W. Kohn and L. J. Sham, Phys. Rev., 1965, 140, A1133-A1138.

30 P. Hohenberg and W. Kohn, Phys. Rev., 1964, 136, B864B871.

31 G. Kresse, J. Non-Cryst. Solids, 1995, 193, 222-229.

32 G. Kresse and J. Furthmuller, Comput. Mater. Sci., 1996, 6, 15-50.

33 G. Kresse and J. Furthmuller, Phys. Rev. B: Condens. Matter Mater. Phys., 1996, 54, 11169-11186.

34 G. Kresse and D. Joubert, Phys. Rev. B: Condens. Matter Mater. Phys., 1999, 59, 1758-1775.

35 A. D. Bochevarov, E. Harder, T. F. Hughes, J. R. Greenwood, D. A. Braden, D. M. Philipp, D. Rinaldo, M. D. Halls, J. Zhang and R. A. Friesner, Int. J. Quantum Chem., 2013, 113, 21102142.

36 K. Fukui, Acc. Chem. Res., 1981, 14, 363-368.

37 Q. An, W. Liu, W. A. Goddard III, T. Cheng, S. V. Zybin and H. Xiao, J. Phys. Chem. C, 2014, 118, 27175-27181.

38 C.-C. Ye, Q. An, W. A. Goddard III, T. Cheng, W.-G. Liu, S. V. Zybin and X.-H. Ju, J. Mater. Chem. A, 2015, 3, 19721978. 